\title{
Transareolar pulmonary bullectomy for primary spontaneous pneumothorax
}

\author{
Jian-Bo Lin, MD, Jian-Feng Chen, MD, PhD, Fan-Cai Lai, MD, PhD, Xu Li, MD, PhD, and
}

Ming-Lian Qiu, MD, PhD

\begin{abstract}
Background: Conventional 3-port video-assisted thoracoscopic surgery is the classic approach for the diagnosis and treatment of primary spontaneous pneumothorax. Transareolar pulmonary bullectomy rarely has been attempted. This study aimed to evaluate the feasibility and safety of this novel minimally invasive technique in managing primary spontaneous pneumothorax.
\end{abstract}

Methods: From January 2013 to December 2014, a total of 112 male patients with primary spontaneous pneumothorax underwent transareolar pulmonary bullectomy by use of a 5-mm thoracoscope.

Results: All procedures were performed successfully, with a mean operating time of 26.5 minutes. The mean length of transareolar incision for the main operation was $2.0 \pm 0.2 \mathrm{~cm}$, the mean length of incision for the camera port was $0.6 \pm 0.1 \mathrm{~cm}$, and the mean postoperative cosmetic score was $3.0 \pm 0.8$. All patients regained consciousness rapidly after surgery. One hundred seven patients $(95.5 \%)$ were discharged on postoperative day 2 or 3 , with the remainder discharged on postoperative day 4 or 5 . Postoperative complications were minor. At 6 months postoperatively, there was no obvious surgical scar on the chest wall, and no patient complained of postoperative pain. No recurrent symptoms were observed. One-year follow-up revealed an excellent cosmetic result and degree of satisfaction.

Conclusions: Transareolar pulmonary bullectomy is a safe and effective therapeutic procedure for primary spontaneous pneumothorax caused by pulmonary bullae. The incision is hidden in the areola with excellent cosmetic effects. This novel procedure shows promise as a treatment of primary spontaneous pneumothorax. (J Thorac Cardiovasc Surg 2016;152:999-1005)

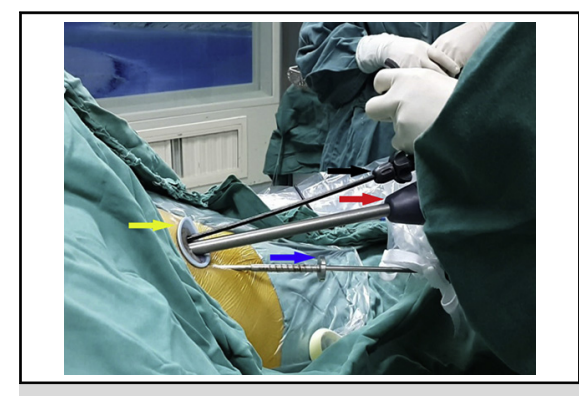

Transareolar pulmonary bullectomy procedure. The colored arrows indicate the following: black, flexible endograsper; red, endoscopic linear stapling device yellow, wound protector; blue, 5- $\mathrm{mm} 30^{\circ}$ thoraco scope and trocar.

\section{Central Message}

Transareolar pulmonary bullectomy for primary spontaneous pneumothorax provided excellent cosmetic and clinical outcomes in 112 patients.

\section{Perspective}

The procedure resulted in a short hospital stay, minimal postoperative pain, no major complications, an excellent cosmetic outcome, and no recurrence in a minimum 1-year follow-up duration. Transareolar pulmonary bullectomy provides several advantages compared with traditional PSP treatment techniques.

See Editorial Commentary page 1006.
In most institutions, the diagnosis and treatment of primary spontaneous pneumothorax (PSP) usually is performed through conventional 3-port video-assisted thoracoscopic

\footnotetext{
From the Department of Thoracic Surgery, First Affiliated Hospital of Fujian Medical University, Fuzhou, People's Republic of China.

J-B. L. and J-F. C. contributed equally to this study, and both should be considered first author.

Received for publication Jan 16, 2016; revisions received May 11, 2016; accepted for publication June 19, 2016; available ahead of print Aug 2, 2016.

Address for reprints: Fan-Cai Lai, MD, PhD, Department of Thoracic Surgery, First Affiliated Hospital of Fujian Medical University, \#20 Chazhong Rd, Fuzhou, Fujian 350005, People's Republic of China (E-mail: 291257010@qq.com). $0022-5223 / \$ 36.00$

Copyright (c) 2016 by The American Association for Thoracic Surgery http://dx.doi.org/10.1016/j.jtcvs.2016.06.023
}

surgery (cVATS). cVATS leaves 3 obviously visible scars on the chest wall, resulting in a permanent cosmetic defect. Furthermore, in cVATS the second operation hole is placed through the seventh intercostal space at the posterior axillary line where the chest wall muscles are thick and the intercostal space is narrow; this often induces intercostal nerve injury, which results in numbness or paresthesia,

Scanning this QR code will take you to a procedural video.

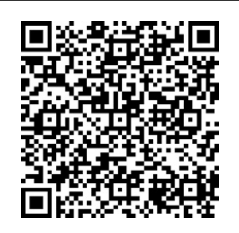




$$
\begin{aligned}
& \text { Abbreviations and Acronyms } \\
& \begin{aligned}
\mathrm{CT} & =\text { computed tomography } \\
\mathrm{cVATS} & =\text { conventional 3-port video-assisted } \\
& \text { thoracoscopic surgery } \\
\mathrm{PSP} & =\text { primary spontaneous pneumothorax } \\
\mathrm{SITS} & =\text { single-incision thoracoscopic surgery } \\
\mathrm{VAS} & =\text { visual analog scale } \\
\mathrm{CXR} & =\text { chest } \mathrm{x}-\mathrm{ray}
\end{aligned}
\end{aligned}
$$

and postoperative wound-related pain. Single-incision thoracoscopic surgery (SITS) has been reported, but it is not used widely because of its poor maneuverability and the requirement for expensive special or disposable devices. ${ }^{1}$ Considering the disadvantages of these pneumothorax treatment procedures, we designed a transareolar pulmonary bullectomy for pneumothorax (Video 1) at our hospital in January 2013. In this article, we report our initial experience with transareolar pulmonary bullectomy for pneumothorax.

\section{METHODS \\ Patient Selection}

From January 2013 to December 2014, a total of 127 male patients with PSP underwent pulmonary bullectomy at our institution. Among them, 112 cases $(88.2 \%)$ underwent transareolar pulmonary bullectomy by use of a 5$\mathrm{mm}$ thoracoscope. Patient characteristics are listed in Table 1. This study was approved by the Institutional Review Board and Ethics Committee of the First Affiliated Hospital of Fujian Medical University (No. 201301, January, 2013). All patients received a preoperative routine blood examination, cardiological consultation, and computed tomography (CT) scan of the chest. A detailed medical history, the degree of symptoms, and the distribution of pulmonary bulla also were documented. All patients signed their informed consent at least 1 day before surgery after careful explanation of the procedure and goals of the study.

Inclusion criteria were age $>16$ years and $<50$ years; male patients with PSP; no history of thoracic surgery or severe chest wall deformity. Exclusion criteria were age $<16$ years and $>50$ years; female patients; history of

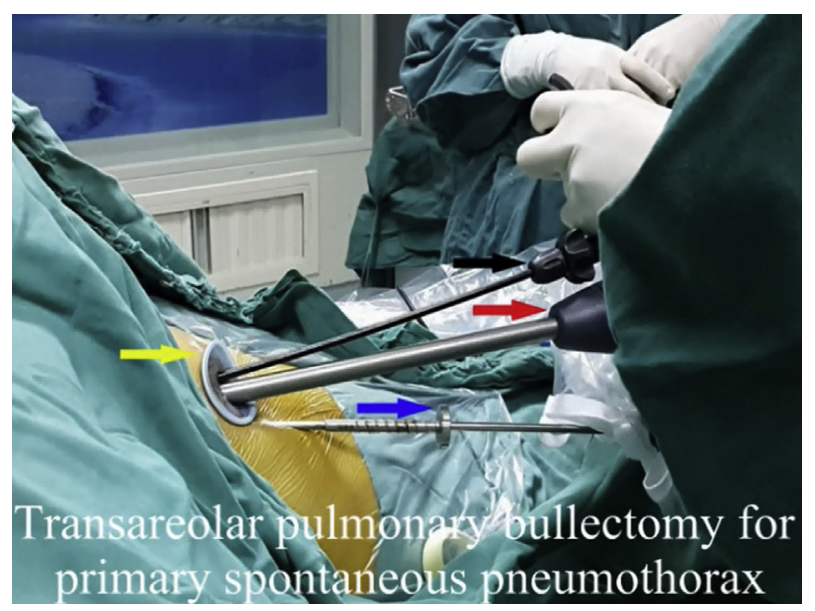

VIDEO 1. Transareolar pulmonary bullectomy procedure. Video available at http://www.jtcvsonline.org/article/S0022-5223(16)30653-5/addons.
TABLE 1. Patient characteristics

\begin{tabular}{ll}
\hline \multicolumn{1}{c}{ Characteristics } & \multicolumn{1}{c}{ Value } \\
\hline No. of patients & 112 \\
Mean age/range, y & $24(16-49)$ \\
Mean BMI/range, $\mathrm{kg} / \mathrm{m}^{2}$ & $20.6(18.2-23.4)$ \\
Positive family history, yes/no & $6 / 106$ \\
Distribution of pulmonary bulla, $\mathrm{n}(\%)$ & \\
Left upper lobe of lung only & $57 / 50.9$ \\
Plus left lower lobe of lung & $3 / 2.7$ \\
Right upper lobe of lung only & $48 / 42.9$ \\
Plus right middle lobe of lung & $2 / 1.8$ \\
Plus right middle and lower lobe of lung & $2 / 1.8$ \\
\hline
\end{tabular}

BMI, Body mass index.

thoracic surgery or severe chest wall deformity; upper airway and maxillofacial injury or deformity; lung, pleural, or heart diseases.

\section{Surgical Procedure}

All patients were positioned on the operating table in a semi-sitting position with arms in abduction and underwent healthy side 1-lung ventilation (Figure 1, A). A 5-mm incision for the camera port was made through the fourth intercostal space at the lower edge of the areola (Figure $1, B$ ). We used a 5-mm $30^{\circ}$ thoracoscope (Karl Storz GmbH \& Co. KG, Tuttlingen, Germany) to observe the thoracic cavity, especially the area surrounding the bulla identified on computed tomography. When the lesions were identified and adhesions were minimal, a second $2.0-\mathrm{cm}$ port was introduced through the third intercostal space at the upper edge of the areola as the main operational incision, and a wound protector (ENDO KEEPER; NELIS, Bucheon, Korea) was fixed on the incision window. Next, the endograsper (Covidien, Mansfield, Mass) and the endoscopic linear stapling device (ENDO-GIA, Johnson \& Johnson, Mansfield, Mass) were inserted into the window for wedge-shaped excision of the lung (Figure 1, B).

After resection, warm saline water was poured into the thorax to test for air leakage; fibrin glue was sprayed to the lung surface and the lung resection area. Then, a piece of gauze with iodopovidone was used to perform both mechanical abrasion and chemical pleurodesis on the chest wall. A 2-mm subclavian vein tube was placed through the second intercostal space at the mid-clavicular line (Figure 1, $A$ and $C$ ), whose lower end was later connected to a thoracic drainage bottle with negative pressure (Figure 2,D). A second 2-mm subclavian vein tube was placed through the seventh intercostal space at the middle axillary line, whose lower end was later connected to a drainage bag (Figure 2, $B$ and $D$ ). All procedures were completed by insertion of a $14 \mathrm{~F}$ chest tube through the incision window, and the lung was reinflated under visual control. The chest tube was aspirated while the anesthesiologist ventilated the patient manually, exerting continuous positive pressure for a few seconds before the drain subsequently was removed. Compont Medical Adhesive (Compont Medical Devices Co., LTD, Beijing, China) was used to dress wounds after the muscle and subcutaneous tissue were sutured (Figure 3, A). The subclavian vein tube was removed ${ }^{2}$ when: (1) the lung was expanded fully without pleural effusion on chest radiography; (2) there was no air leakage through the chest tube; and (3) the amount of drainage was less than $100 \mathrm{~mL}$ per day.

\section{Data Collection and Follow-up}

The operating time, resuscitation time, hospital stay, incision length, pain score, and complications were recorded. The patients were followed up for 12-26 months by hospital visits (53 cases, 47.3\%), telephone (38 cases, $33.9 \%$ ), or e-mail ( 21 cases, $18.8 \%$ ). The mean duration of follow-up was $15.6 \pm 3.2$ months. Patients were required to fill out a 

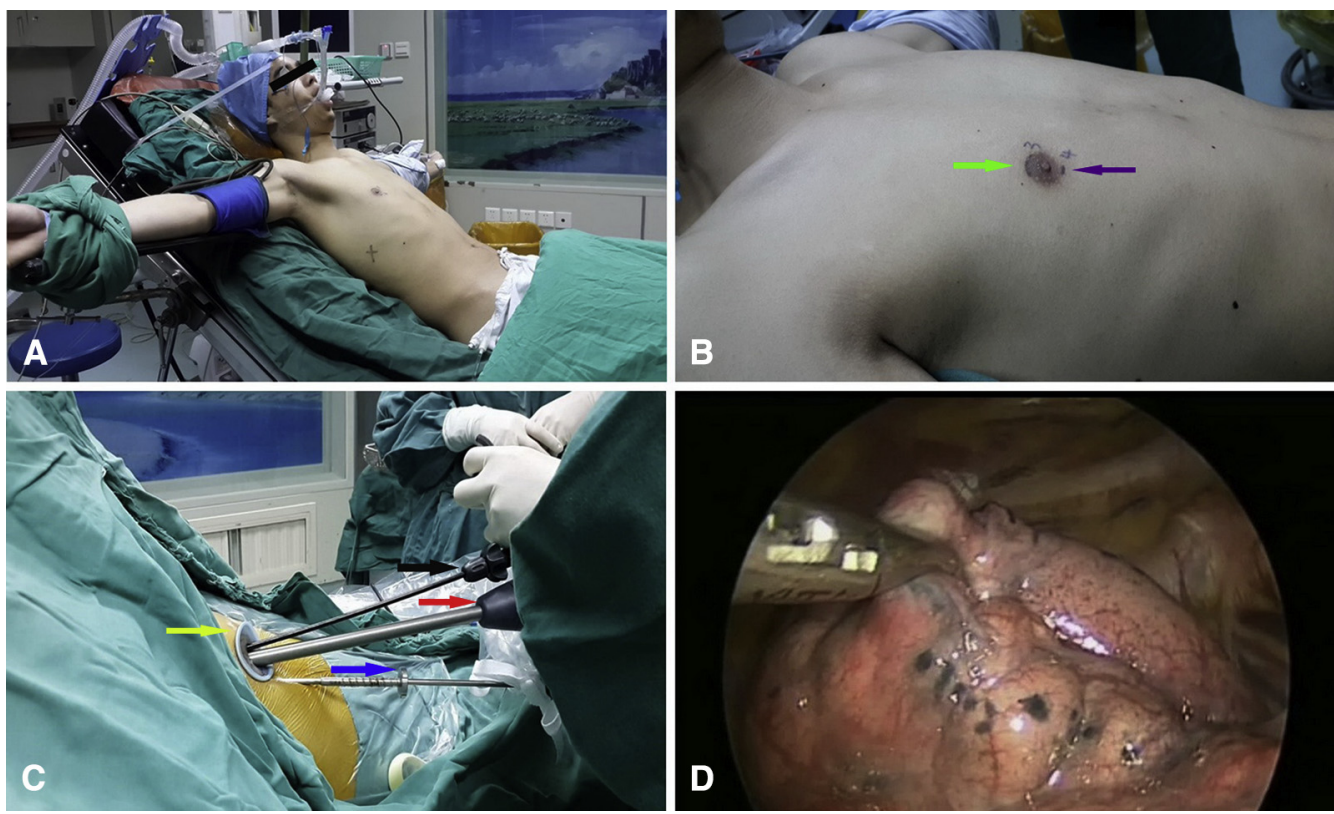

FIGURE 1. A, The semi-sitting position used during surgery. B, Transareolar incision marked before operation. The colored arrows indicate the following: green, the main operational incision; purple, incision for the camera port. C, Transareolar pulmonary bullectomy procedure. The colored arrows indicate the following: black, endograsper; red, endoscopic linear stapling device; yellow, wound protector; blue, 5-mm $30^{\circ}$ thoracoscope and trocar. D, Transareolar endoscopic view of right thoracic cavity.

detailed questionnaire (Table 2). The data collected include resolution of symptoms, cosmetic scores, satisfaction scores, residual pain, and incidence of recurrence. The recurrence of pneumothorax was evaluated by recurrent symptoms such as sudden stethalgia, chest congestion, or dyspnea, etc. Patients routinely were asked to have a chest x-ray once they had recurrent symptoms during follow-up.
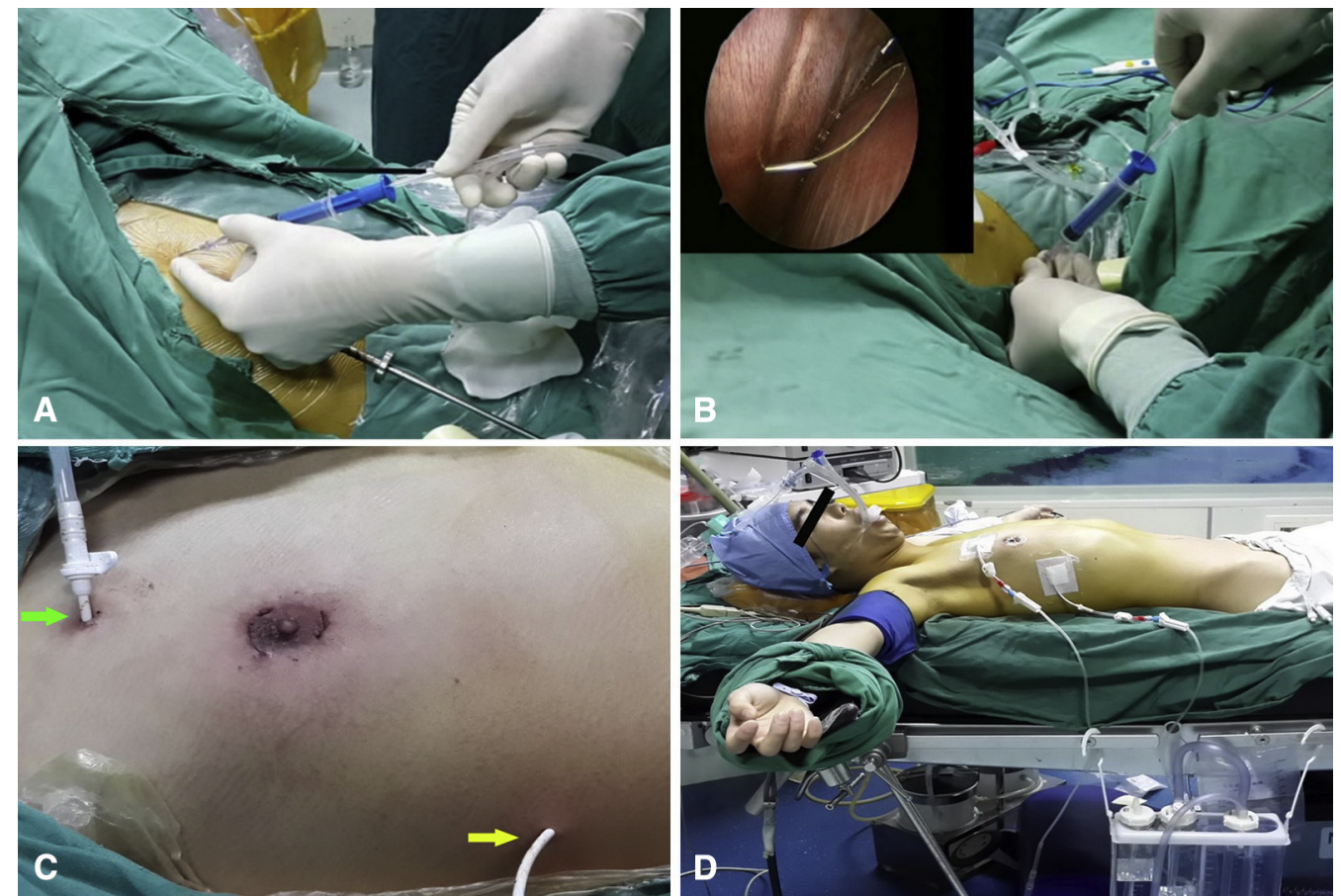

FIGURE 2. A, Placing a 2-mm subclavian vein tube through the second intercostal space at the mid-clavicular line. B, Placing a second 2-mm subclavian vein tube through the seventh intercostal space at the middle axillary line. C, Transareolar incision and subclavian vein tube view. The colored arrows indicate the placement of 2-mm subclavian vein tube. D, Connecting subclavian vein tube to thoracic drainage bottle at second intercostal space and drainage bag at seventh intercostal space. 

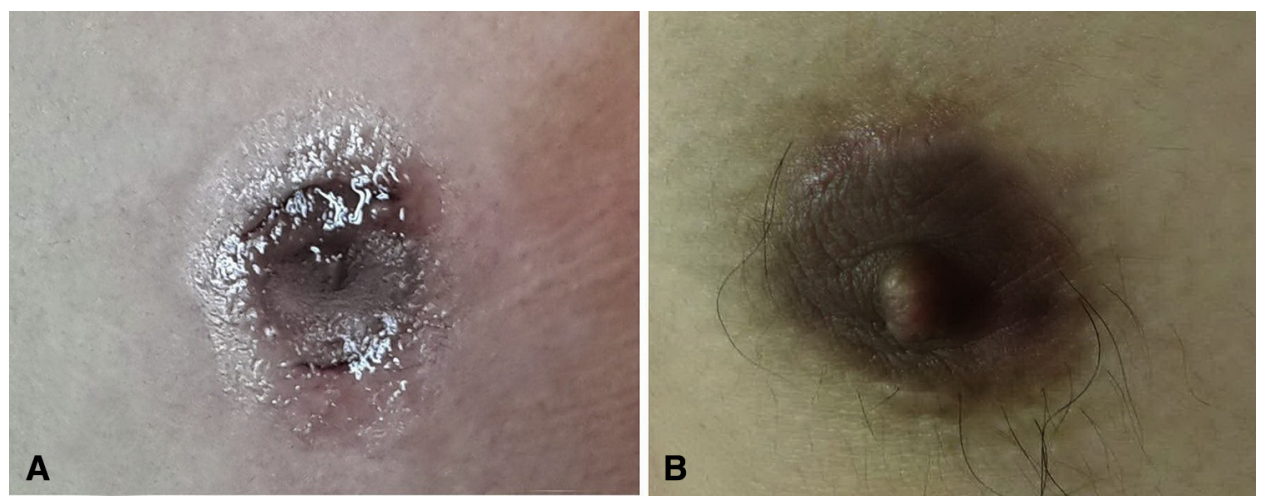

FIGURE 3. A, Dressing wounds by using Compont Medical Adhesive. B, Photograph of a patient 8 months after surgery showing the absence of any obvious surgical scar on the chest wall.

\section{RESULTS}

All procedures were performed successfully in all patients, with a mean operating time of 26.5 minutes. There was no operative mortality and no conversion to open procedure. The mean drainage time was 3.6 day, with an average amount of drainage of $120 \pm 25 \mathrm{~mL} /$ day. Hospital stay was very short, with 107 patients $(95.5 \%)$ discharged on the second or third postoperative day and the remainder discharged on the fourth or fifth postoperative day. The mean length of transareolar incision for the main operation was $2.0 \pm 0.2 \mathrm{~cm}$, and the mean length of the incision for the camera port was $0.6 \pm 0.1 \mathrm{~cm}$ with the 5 -mm small-scale scope. The mean postoperative cosmetic score was $3.0 \pm 0.8$. Nine patients were diagnosed as postoperative pneumonia by combination of chest radiographs findings with clinical and laboratory data. Among them, 3 patients were long-term smokers, and 4 patients did not go to the hospital for treatment after several days of chest discomfort and shortness of breath. All of these cases were resolved by

\section{TABLE 2. Follow-up questionnaire}

\section{Question response}

1. Cosmetic results

Verbal response scale (VRS): 1 dissatisfied/2 accepted/3 satisfied/4 perfect

2. Postoperative pain

Visual analog scale (VAS) pain score: from 0 "no pain" to 10 "worst pain imaginable"

3. Recurrent pneumothorax

No/yes

Location: left lung, right lung

Symptoms: sudden stethalgia, chest congestion, dyspnea, or others Degree: mild/moderate/severe*

4. Satisfaction

VAS satisfaction score: very satisfied (9-10)/satisfied (6-8)/ dissatisfied (3-5)/very dissatisfied (0-2)

*The degree of postoperative pneumothorax was classified as follows: mild, lung collapse is less than $30 \%$; moderate, lung collapse is between $30 \%$ and $50 \%$; severe, lung collapse is more than $50 \%$. intravenous antibiotics and did not require further intervention. No wound infection was observed in any patient.

Follow-up was $100 \%$ complete. Eighty-six patients $(76.8 \%)$ returned the questionnaire immediately, and 26 patients $(23.2 \%)$ returned it after a reminder or repeated e-mailing. Outcomes of follow-up after surgery are shown in Table 3. The response rates at the time of discharge and 6 and 12 months postoperatively were $100 \%$. No recurrent symptoms were observed in our study. Postoperative pain affected 26 patients $(23.2 \%)$ at the time of discharge. According to a visual analog scale (VAS) pain score, 24 cases $(92.3 \%)$ were considered mildly painful (mean VAS score $2.31 \pm 0.66)$, and 2 cases $(7.7 \%)$ were considered moderately painful (mean VAS score $5.66 \pm 0.57$ ). No patient required analgesia. None of the patients complained about postoperative pain 6 months after surgery. Our procedure had an excellent cosmetic result (Table 3; Figures 3, $B$, and 4 ) and degree of satisfaction (Table 3 ) during follow-up.

\section{DISCUSSION}

We successfully performed transareolar pulmonary bullectomy as a treatment for PSP in all 112 male patients. According to our experience, if $\mathrm{CT}$ scan of the chest

\section{TABLE 3. Outcomes of postoperative follow-up}

\begin{tabular}{lccc}
\hline \multicolumn{1}{c}{ Demographics } & Discharge & $\mathbf{6}$ mo & $\mathbf{1 2}$ mo \\
\hline Resolution of symptoms, & $112(100)$ & $112(100)$ & $112(100)$ \\
n (\%) & & & \\
Mean cosmetic score, VRS & $3.0 \pm 0.8$ & $3.4 \pm 0.3$ & $3.7 \pm 0.4$ \\
Degree of Postoperative pain, $\mathrm{n}(\%)$ & & \\
Mild & $24(92.3 \%)$ & $0(0)$ & $0(0)$ \\
Moderate & $2(7.7 \%)$ & $0(0)$ & $0(0)$ \\
Severe & $0(0)$ & $0(0)$ & $0(0)$ \\
Degree of satisfaction, n (\%) & & & \\
Very satisfied & $112(100)$ & $109(97.3)$ & $107(95.5)$ \\
Satisfied & $0(0)$ & $3(2.7)$ & $5(4.4)$ \\
Dissatisfied & $0(0)$ & $0(0)$ & $0(0)$ \\
Very dissatisfied & $0(0)$ & $0(0)$ & $0(0)$ \\
\hline
\end{tabular}

VRS, Verbal response scale. 

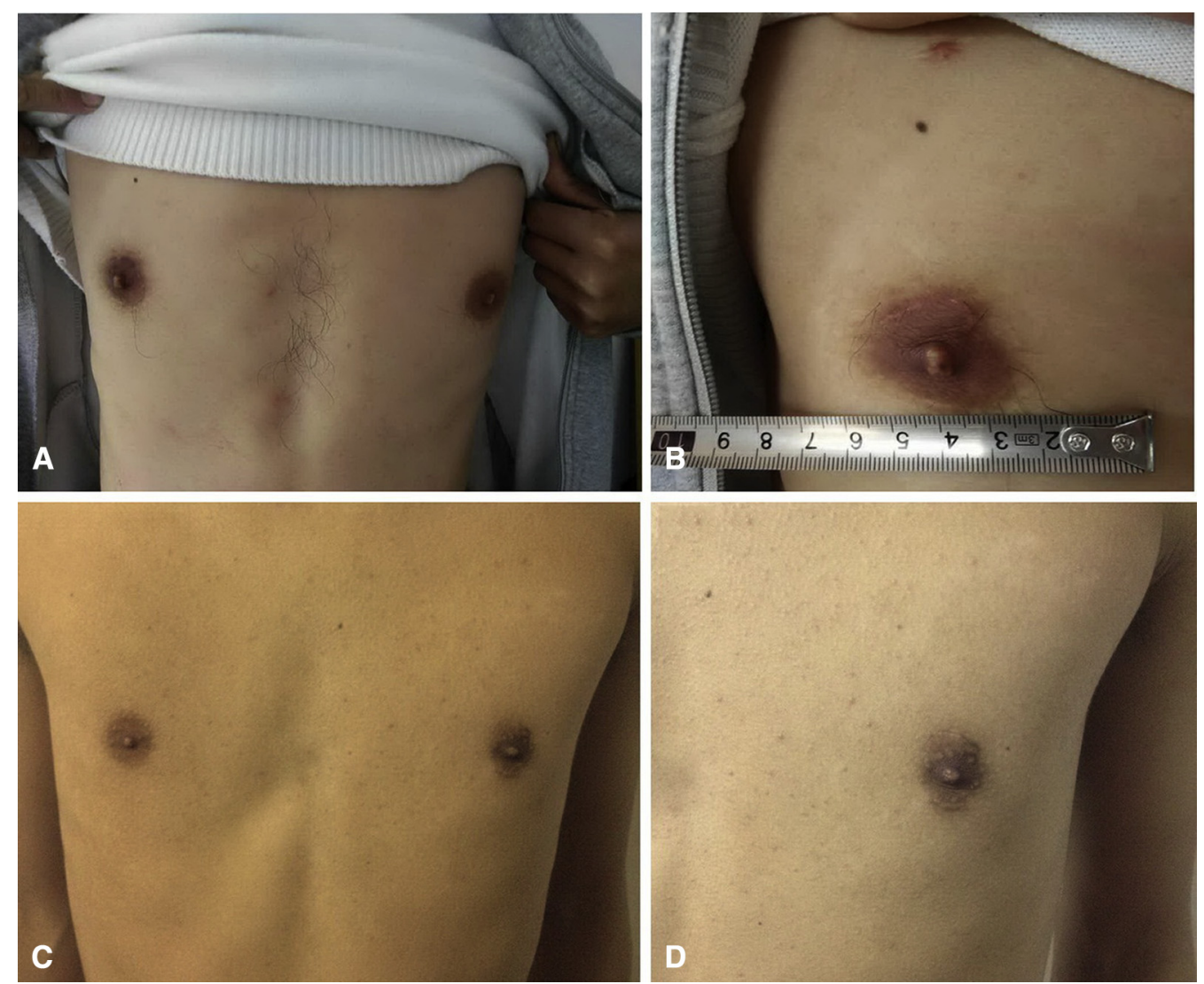

FIGURE 4. A, B, The surgical scar was hidden in the areola of a patient 8 months after surgery. C, D, Photograph of another patient 1 year after surgery showing the absence of any obvious surgical scar on the chest wall.

demonstrated obvious bleb that implied a high recurrence rate of pneumothorax, we recommended operation at the first pneumothorax. If CT scan of the chest showed no significant bleb, we tended to take measures to observe it conservatively when lung collapse was less than $30 \%$ and draining it when lung collapse was more than $30 \%$. Female or obese patients (body mass index $>30 \mathrm{~kg} / \mathrm{m}^{2}$ ) were not recommended for this procedure because of their developed mammary gland, relatively instable location of areola, or fatty chest wall. The procedure resulted in a short hospital stay, minimal postoperative pain, no major complications, an excellent cosmetic outcome, and no recurrence in a minimum follow-up duration of 1 year. Transareolar pulmonary bullectomy appears to have several advantages compared with traditional PSP treatment techniques.

Since the 1990s, cVATS has become the preferred treatment for PSP because of its many advantages. ${ }^{3}$ Thoracoscopic pulmonary bulla resection is an effective treatment for patients experiencing PSP. Although cVATS is accepted widely as the standard procedure for PSP in most institutions, this technique has some shortcomings. First, traditional thoracoscopic pulmonary bulla resection must be performed via 3 incisions, 1 of which (the second operation hole) is placed through the seventh intercostal space at the posterior axillary line where the chest wall muscles are thick and the intercostal space is narrow; the frequent importing and exporting of instruments through this incision easily induces intercostal nerve injury, resulting in numbness or paresthesia, and postoperative wound-related pain. These chronic postoperative problems are caused mainly by intercostal nerve injury incurred when the trocars are introduced into the intercostal space. ${ }^{4,5}$ Second, cVATS leaves 3 obviously visible scars on the chest wall, which results in a permanent cosmetic defect. Because PSP is prevalent in young people, especially in tall and slender individuals, cosmetic outcome is an important consideration in thoracic surgery.

Attempts at improving cosmetic outcome have resulted in the development of a series of minimally invasive surgical procedures. Reduced port surgery has been reported. For 2-port video-assisted thoracoscopic surgery, Tsuboshima and colleagues ${ }^{6}$ reported the feasibility of using an EndoClose (Covidien) device with puncture. Endo-Close is a device used to pull the anchoring thread via a $1.5-\mathrm{cm}$ puncture incision at the level of the seventh intercostal space at the median axillary line for the camera port, a $1.5-\mathrm{cm}$ incision at the level of the fourth intercostal space at the anterior axillary line for the working port, and a 2-mm puncture at 
the level of the fifth intercostal space at the median axillary line. For SITS, Rocco and colleageues ${ }^{7}$ reported the feasibility of bendable devices, and Berlanga and Gigirey ${ }^{8}$ used an SITS port (Covidien) that had been used already in cholecystectomy; however, this early kind of reduced port surgery including SITS is not used widely because of its poor maneuverability and the requirement for expensive special devices or disposable devices. Moreover, it is difficult for the surgeon to manipulate the thoracoscope, endoscopic forceps, and stapler simultaneously through a single incision of approximately $2.0 \mathrm{~cm} .{ }^{1}$ If the incision is extended, the cosmetic result of SITS is less satisfactory.

To obtain better cosmetic results in pulmonary bullectomy, we designed a transareolar procedure for PSP in which the surgical scar is hidden in the areola. We were inspired by the success of our previously reported thoracoscopic thoracic sympathectomy for the treatment of palmar hyperhidrosis by single transareolar incision in 2011 with which achieved good efficacy and excellent cosmetic results. ${ }^{9}$

Transareolar pulmonary bullectomy presents several potential advantages. First, the incision is hidden in the areola. With the use of wound adhesive bonding, there is no significant postoperative surgical scar, especially for patients with dark areolar pigmentation (Figures $3, B$, and $4, A$ and $B$ ). Second, compared with the axillary approach, the areola is relatively thin at the chest, and there are fewer intercostal vessels and nerves. We speculate that the transareolar path could significantly reduce chest injury, thus greatly reducing postoperative pain. Third, when the traditional lateral position is used, changing position after double-lumen endotracheal intubation may induce displacement of the intubation, which will increase the difficulty of operation because of the lung collapse on the surgical side. Use of the transareolar path with the patient in a semi-sitting position means that the body of the patient does not need to be turned sideways, which greatly reduces the likelihood of intubation displacement. This semi-sitting position also is very convenient for conducting simultaneous bilateral transareolar pulmonary bullectomy when needed.

Fourth, there is some controversy with regard to the type of pleurodesis to be performed in patients with PSP. Talc poudrage is the treatment of choice for recurrent malignant pleural effusion or in spontaneous pneumothorax in elderly patients, which has an overall success rate of $90 \%{ }^{10-13}$; however, its use in young patients is controversial because of the immediate postsurgical side effects (severe hypoxemia, respiratory distress syndrome, or pneumonitis). ${ }^{14}$ In our study, a piece of gauze with iodopovidone was used to perform both mechanical abrasion and chemical pleurodesis on the chest wall, which was not only equally efficacious to talc pleurodesis ${ }^{15}$ but also safe to young patients. Fifth, the introduction of minimally invasive surgery in thoracic surgery lowered postoperative pain ${ }^{16}$; therefore, the pain caused by drainage of the chest became more prominent. ${ }^{17}$ The size of the traditional chest tube generally is between 26 and 32 . Large chest tubes not only induce morbidity such as pain, and increased risk of infection and immobilization, ${ }^{18-20}$ but also prolong the length of hospital stays, which is a main discomfort and major complaint of patients after thoracic surgery. The needle $2-\mathrm{mm}$ subclavian vein tube we used that was placed through the second intercostal space at the mid-clavicular line and the seventh intercostal space at the middle axillary line instead of a traditional chest tube is an excellent solution; it is not only minimally invasive, painless, and seldom induces discomfort, but also is removed easily and provides an excellent cosmetic outcome. Last, we believe that the transareolar approach shortens the surgical path compared with the traditional lateral thoracic path; this is better for the operation field exposure, especially for apical bullae, and reduces the surgical difficulty.

\section{CONCLUSIONS}

This study demonstrated that transareolar pulmonary bullectomy is a safe and effective therapeutic procedure for PSP caused by pulmonary bullae that gives an excellent cosmetic and clinical outcome. This novel procedure is a promising new approach for the treatment of PSP.

\section{Conflict of Interest Statement}

Authors have nothing to disclose with regard to commercial support.

\section{References}

1. Tsuboshima K, Wakahara T, Matoba Y, Miyauchi H, Hayashi C, Kobayashi I, et al. Single-incision thoracoscopic surgery using a chest wall pulley for lung excision in patients with primary spontaneous pneumothorax. Surg Today. 2015;45:595-9.

2. Cerfolio RJ, Bryant AS, Skylizard L, Minnich DJ. Optimal technique for the removal of chest tubes after pulmonary resection. J Thorac Cardiovasc Surg. 2013;145:1535-9.

3. Min X, Huang Y, Yang Y, Chen Y, Cui J, Wang C, et al. Mechanical pleurodesis does not reduce recurrence of spontaneous pneumothorax: a randomized trial. Ann Thorac Surg. 2014;98:1790-6.

4. Sihoe AD, Cheung CS, Lai HK, Lee TW, Thung KH, Yim AP. Incidence of chest wall paresthesia after needlescopic video-assisted thoracic surgery for palmar hyperhidrosis. Eur J Cardiothorac Surg. 2005;27:313-9.

5. Dumont P, Denoyer A, Robin P. Long-term results of thoracoscopic sympathectomy for hyperhidrosis. Ann Thorac Surg. 2004;78:1801-7.

6. Tsuboshima K, Matoba Y, Sato M, Kobayashi I, Ohue H, Watanabe Y, et al. Evaluation of 2 ports video-assisted thoracoscopic surgery (VATS) using endo-close for primary spontaneous pneumothorax. Kyobu Geka. 2013;66:210-3.

7. Rocco G, Martin-Ucar A, Passera E. Uniportal VATS wedge pulmonary resection. Ann Thorac Surg. 2004;77:726-8.

8. Berlanga LA, Gigirey O. Uniportal video-assisted thoracic surgery for primary spontaneous pneumothorax using a single-incision laparoscopic surgery port: a feasible and safe procedure. Surg Endosc. 2011;25:2044-7.

9. Tu YR, Lai FC, Li X, Lin M, Duan HB, Fu CG, et al. Trans-areola single port endoscopic thoracic sympathectomy for the treatment of palmar hyperhidrosis: a new surgical approach [in Chinese]. Zhonghua Yi Xue Za Zhi. 2011;91:3131-3.

10. Tschopp JM, Brutsche M, Frey JG. Treatment of complicated spontaneous pneumothorax by simple talc pleurodesis under thoracoscopy and local anesthesia. Thorax. 1997;52:329-32.

11. Weissberg D, Ben-Zeev I. Talc pleurodesis. Experience with 360 patients. J Thorac Cardiovasc Surg. 1993;106:689-95.

12. Kennedy L, Sahn SA. Talc pleurodesis for the treatment of pneumothorax and pleural effusion. Chest. 1994;106:1215-22. 
13. Acton V. Is pleurodesis for the treatment of primary spontaneous pneumothorax a misnomer-and if it works, does it matter? J Thorac Cardiovasc Surg. 2015;149: 397-8.

14. Moreno-Merino S, Congregado M, Gallardo G, Jimenez-Merchan R, Trivino A, Cozar F, et al. Comparative study of talc poudrage versus pleural abrasion for the treatment of primary spontaneous pneumothorax. Interact Cardiovasc Thorac Surg. 2012;15:81-5

15. Agarwal R, Paul AS, Aggarwal AN, Gupta D, Jindal SK. A randomized controlled trial of the efficacy of cosmetic talc compared with iodopovidone for chemical pleurodesis. Respirology. 2011;16:1064-9.

16. McKenna RJ Jr, Houck W, Fuller CB. Video-assisted thoracic surgery lobectomy: experience with 1100 cases. Ann Thorac Surg. 2006;81:421-5.

17. Göttgens KW, Siebenga J, Belgers EH, van Huijstee PJ, Bollen EC. Early removal of the chest tube after complete video-assisted thoracoscopic lobectomies. Eur J Cardiothorac Surg. 2011;39:575-8.
18. Gomez-Caro A, Roca MJ, Torres J, Cascales P, Terol E, Castaner J, et al. Successful use of a single chest drain postlobectomy instead of two classical drains: a randomized study. Eur J Cardiothorac Surg. 2006;29:562-6.

19. Okur E, Baysungur V, Tezel C, Sevilgen G, Ergene G, Gokce M, et al. Compar ison of the single or double chest tube applications after pulmonary lobectomies. Eur J Cardiothorac Surg. 2009:35:32-5.

20. Younes RN, Gross JL, Aguiar S, Haddad FJ, Deheinzelin D. When to remove a chest tube? A randomized study with subsequent prospective consecutive validation. J Am Coll Surg. 2002;195:658-62.

Key Words: pulmonary bullae, spontaneous pneumothorax, areolar approach, video-assisted thoracoscopic surgery

Readers who found these articles interesting may also like to read the following papers found in recent and future issues of our sister publications, Seminars in Thoracic and Cardiovascular Surgery and Operative Techniques in Thoracic and Cardiovascular Surgery!

\section{Thoracic: Other Thoracic Surgical Papers}

News and Views: Recent and Future Developments in Chest Wall Reconstruction. Calvin Ng. Semin Cardiovasc Surg 2015; Summer; 27(2):234-239.

Current Readings: What the Surgeon Needs to Know About Databases. Alessandro Brunelli. Semin Thorac Cardiovasc Surg 2015; Summer; 27(2):251-256.

Original Submission: Endobronchial Treatment of bronchopleural fistulas by using Intrabronchial valve system: a case series. Eitan Podgaetz. Semin Thorac Cardiovasc Surg 2015; Summer; 27(2):218-222.

Editorial Commentary: One-Way Valves to the Rescue or Bronchopleural Fistulae. Eric J. Seeley. Semin Thorac Cardovasc Surg 2015; Summer; 27(2):223-224.

Tracheal Surgery: Posterior Splinting Tracheoplasty for Tracheomalacia. Cameron D. Wright. Oper Tech Thorac Cardiovasc Surg 2015; Spring; 20(1):31-45.

Laryngeal Resection and Reconstruction. John D. Mitchell. Oper Tech Thorac Cardiovasc Surg 2015; Spring; $20(1)$ :46-62.

Video-Assisted Thoracoscopic Segmentectomy of the Lower Lobe: Superior and Basilar Segmentectomy. Nathaly P. Llore. Oper Tech Thorac Cardiovasc Surg 2015; Summer; 20(2):162-175.

Robotic First Rib Resection. Eric Strother. Oper Tech Thorac Cardiovasc Surg 2015; Summer; 20(2):178-188.

Surgical management of esophageal perforation. Manu Sancheti. Oper Tech Thorac Cardiovasc Surg 2015; Autumn; 20(3):234-250.

Endoscopic techniques for the management of esophageal perforation. Shanda Blackmon. Oper Tech Thorac Cardiovasc Surg 2015; Autumn; 20(3):251-278. 